\title{
EL ORDEN Y EL DESVÍO: HIBRIDACIÓN GENÉRICA EN UN DÍA CUALQUIERA DE HEBE UHART
}

Javier de Navascués

Universidad de Navarra

jnavascu@unav.es

Resumen: El artículo estudia Un día cualquiera (2015), último libro de cuentos de la escritora argentina Hebe Uhart. Se muestra el carácter híbrido del volumen respecto a su clasificación genérica. Los cuentos de Un día cualquiera mantienen relaciones heterogéneas entre sí. Así, el libro tiene semejanzas con una autobiografía de infancia o con el ciclo de cuentos, pero no equivale exactamente a ninguna de las dos categorías.

Palabras clave: Hebe Uhart, ciclo de cuentos, autobiografía de infancia

\begin{abstract}
The paper analyzes the Un dia cualquiera (2015), last collection of short stories published by the Argentinean writer Hebe Uhart. Regarding to its generic classification, it shows the hybrid character of the volume. The stories of Un dia cualquiera have heterogeneous relations among them. Thus the book shares similarities with childhood autobiographies or cycle of short stories, although it is not equivalent with these categories.
\end{abstract}

Keywords: Hebe Uhart, cycle of short stories, childhood autobiographies

DOI: https://doi.org/10.24029/lejana.2017.10.161

Recibido: el 23 de julio de 2017

Aceptado: el 25 de septiembre de 2017

Publicado: el 4 de noviembre de 2017 


\begin{abstract}
Es curioso lo que me sucede con las personas: al momento de conocerlas, tengo una idea global de quiénes son, con el trato y el paso del tiempo, esa idea se va fragmentando y ya no sé nada más de cómo es el otro, me abandono a las diferentes perspectivas.
\end{abstract}

Hebe Uhart (1997: 21)

Escritora secreta por mucho tiempo, Hebe Uhart (Moreno, Provincia de Buenos Aires, 1936) ha atravesado ya los límites de una recepción para iniciados para convertirse en una figura indispensable de la narrativa breve de su país. Sus primeros libros Dios, San Pedro y las almas (1962) y Eli, Eli, lamma sabachtani (1963), vivieron "un anonimato casi perfecto", en palabras de Elvio Gandolfo (2004: 9), debido sobre todo a su modesta circulación. Con altos y bajos en cuanto a la representatividad de las editoriales que la alojaron, su producción ha ido abriéndose paso hasta figurar como una de las obras de referencia del cuento argentino actual.

Los críticos que se han referido a los relatos de Uhart han merodeado en torno a ideas como la falsa ingenuidad, el humorismo o la mirada extrañada. Otro elemento no menos interesante es el de la relación complicada que mantienen sus narraciones con cualquier tentativa de clasificación de la realidad. No me refiero tanto a la dificultad de encasillar la obra de Uhart dentro de una determinada tradición literaria, tópico crítico algo impresionista en el que podríamos caer con apresuramiento. ${ }^{1}$ Más bien, se trata de una consciente operación que emana de sus relatos de manera que la realidad textual poco a poco se va haciendo cada vez más incomprensible, las jerarquías se anulan, los nexos entre una anécdota y otra se van borrando y hasta el bloque completo del discurso acaba rompiendo con los modelos convencionales del relato. Este proceso de implacable y progresiva desorientación impregna una determinada visión del mundo y la estructura misma de sus cuentos.

Este itinerario desde la unidad del conocimiento al fragmento constituye una clave de lectura de notables consecuencias. De ella se deriva un escepticismo fundante, "una radical desconfianza ante las manías modernizadoras, clasificatorias o abstractizantes de cualquier tipo" (Gandolfo, 2009: 14). Entre esas "manías", por supuesto, estaría la tentativa, tan académica y "modernizante", de encajar sus cuentos dentro de una ordenación, un sistema de comprensión que pareciera ignorar el carácter híbrido desde el punto de vista genérico y fragmentario, desde el de la estructura narrativa, que define a las historias de Uhart. En las líneas que siguen trataré de seguir esta hipótesis a partir de su libro Un día cualquiera (2015), considerado uno de sus libros más autobiográficos, ${ }^{2}$ pero que, como veremos enseguida, se desvincula de toda posibilidad de concebirse como un volumen orgánico y coherente.

\footnotetext{
${ }^{1}$ Uhart es una escritora "clasificable", como todos los escritores. Pertenece a una tradición textual, elige a sus precursores y quiere ser leída de una cierta manera. Pienso que, además, de la vinculación de este libro con una determinada tradición autobiográfica argentina, Un día cualquiera puede leerse desde lo que Piglia llamaba una tradición genéricamente híbrida y desordenada de ciertos libros en la literatura argentina: A partir del Facundo, afirma: "Se inaugura así una gran tradición de la literatura argentina. Uno encuentra la misma mezcla, la misma concordancia y amplitud formal en la Excursión de Mansilla, en el Libro extraño de Sicardi, en el Museo de Macedonio, en Los siete locos, en El profesor Landormy de Cancela, en Adán Buenosayres, en Rayuela y, por supuesto, en los cuentos de Borges que son como versiones microscópicas de esos grandes libros (Piglia, 2001: 57). Mansilla es, por cierto, un autor muy apreciado por Uhart. Sobre esta tradición, ver Navascués, 1999.

${ }^{2}$ Ver, por ejemplo, la reseña de Carlos Pardo en El País (2015).
} 


\section{¿Una autobiografía de infancia?}

Los primeros capítulos de Un día cualquiera están dotados de una gran autonomía narrativa, a la vez que se enlazan por el nexo de un mismo personaje principal, la niña, que se identifica con la narradora y la autora desde el pacto autobiográfico, de acuerdo con el conocido término de Lejeune, que el texto plantea a su lector. Por su carácter fragmentado y su temática específica, el volumen pareciera enmarcarse dentro de un patrón singular cuyo antecedente dentro de la literatura argentina podría ser Cuadernos de infancia de Norah Lange. En efecto, el recuento fraccionado de una vida desde la voz femenina e infantil asociaría los dos textos sin dificultad. Hay, sin duda, algunos elementos comunes entre las dos escritoras a partir de la interrogación irónica sobre el mundo y el orden establecidos por la sociedad adulta. Y podríamos tal vez establecer paralelos interesantes a partir de este y otros puntos de partida. Sin embargo, el libro de Hebe Uhart no termina de encajar en el molde de la autobiografía convencional.

De entrada, algunos elementos de la trama nos aconsejan desligar a Un día cualquiera del esquema habitual común del relato autobiográfico. Uno de ellos es el motivo del hallazgo del lenguaje. No pocos narradores y poetas se han visto atraídos por el rescate de sus experiencias infantiles y, desde allí, han establecido que un instante fundamental de sus vidas es la revelación de la potencia comunicativa de las palabras. Por esta razón, uno de los rasgos más frecuentes del relato de infancia o el Childhood, como lo denomina la crítica anglosajona, es el motivo del descubrimiento del poder evocativo del lenguaje. Según Richard Coe, existen una serie de "experiencias arquetípicas" que delimitan la autobiografía de infancia de un escritor, entre las que se encuentra el interés por las palabras en sí mismas, además de la vivencia de los primeros miedos, el aburrimiento, el ingreso en la escuela, las vacaciones o la muerte (Coe, 1984: 169). En el plano de la literatura española del siglo XX, Rafael Alberti rememora en los inicios de La arboleda perdida su fascinación por las canciones populares que escuchaba en su casa familiar:

También aprendí entonces un romance del que me impresionó muchísimo la terminación de una palabra:

\section{Más arribita hay un huerto \\ $y$ en el huerto un naranjel...}

¡Naranjel! ¡Naranjeles! ¡Bellísima variación andaluza que luego, años más tarde, habíamos de emplear tantas veces en nuestras primeras canciones García Lorca y yo! (1997: 27)

Por medio de esta escena y otras que la acompañan en las páginas posteriores, Alberti recupera su temprana vocación por las palabras y la música. La anécdota cobra el valor de una epifanía: el poeta encuentra de pronto su vocación por el verbo en los albores de su vida. Es un punto clave que conforma la imagen que el autor quiere dar de sí mismo, la del individuo destinado a una carrera literaria en la que la belleza autónoma de las palabras conducen al memorialista a su destino de poeta. Experiencias comunes a las de Alberti se pueden encontrar en otras autobiografías de infancia protagonizadas por escritores (Baena, 2000: 480).

Hebe Uhart también desarrolla episodios parecidos, en los que la narradora siente la seducción de las letras de canciones escuchadas en su infancia al hilo de un programa de 
radio, o de poemas que debe memorizar para la escuela. Sin embargo, sus emociones resultan algo problemáticas, porque se mezclan con el desconcierto por el significado de ciertas voces y, sobre todo, por una relación desacralizada con las palabras aprendidas. Lejos del poder de la irradiación luminosa que otros escritores hallan en el lenguaje primigenio de la niñez, el recuerdo se vuelve irónico y desconfiado:

Yo no quería leer nada ni saber de cuartetos, tercetos o sonetos. El año anterior nos habían enseñado unos versos de Antonio Machado, muy lindos:

En el corazón tenía

la espina de una pasión;

logré arrancármela un día:

ya no siento el corazón.

Aguda espina dorada,

quién te pudiera sentir

en el corazón clavada.

[...] Porque aunque no había tenido ni tenía ninguna pasión concreta, el verso de la espina clavada me pegaba fuerte. Pero no quise recordar ningún cuarteto [en clase] y cuando me pidieron el ejemplo, puse:

Venga del aire o del sol

del vino o de la cerveza

cualquier dolor de cabeza

se quita con un Geniol.

Por ese desafío no tuve una nota baja, se ve que nadie me leyó. (57-58)

Antonio Machado sustituido por un anuncio de analgésico. El lenguaje poético suplantado por el registro vulgar del márketing comercial... Uhart desacraliza el topos del hallazgo de la vocación de la escritura alejándola de cualquier idea de predestinación existencial.

Así como la ironía desmitificadora sustituye al fervor en la memoria del lenguaje, $U n$ día cualquiera incorpora, en apariencia, otros elementos propios de la autobiografía de infancia, pero no termina de construirse como una autobiografía de infancia avant la léttre. No se trata solamente de que algunos episodios aislados desmonten los tópicos del género. La misma estructura desautoriza pensar el libro como Childhood. Un día cualquiera se presenta hasta la mitad del volumen como un texto, ciertamente fragmentado, en el que se hilvanan los recuerdos hasta la juventud. Diversos episodios (los retratos familiares, las primeras amistades, los vecinos, etc.) entrarían gustosamente en el modelo del relato autobiográfico de la niñez, lo mismo que la perspectiva infantil, entre distanciada y mimética, entre limitada y lúcida, con la que se enfocan los sucesos. Sin embargo, a la postre, el libro se desvía de la estructura común de este tipo de relatos. Si, por ejemplo, una de las características principales del género es que las fronteras del yo infantil se delimiten ante ciertas experiencias fundantes de la madurez, entonces Un día cualquiera supera esa barrera. Entre los 15 y los 18 años se impone el límite temporal con el que se traza el final de un período de la vida marcado por unos parámetros imaginativos y vitales que no se recuperan nunca más (Coe, 1984: 7). En el capítulo "Maestrita", localizado en los dieciséis años de la protagonista, podría situarse la conclusión de la experiencia de la infancia, ya que el primer ejercicio profesional equivaldría a ese punto, y aparte, esa vivencia más o menos traumática que determina la transformación que conduce a la madurez (Baena, 2000: 481). Sin embargo, no hay tal final. Indiferente al 
shock del abandono de la niñez, el texto de Uhart prosigue avanzando por la juventud y la edad adulta, sin dejar de lado una serie de meandros que, como veremos, destruyen la impresión global de unidad.

\section{El orden}

Si Un día cualquiera se dispone desde la discontinuidad, si los relatos autobiográficos no encajan dentro de un concreto marco temporal y ni siquiera se centran en el mismo protagonista, entonces deberemos renunciar a entenderlo como una narración única. Ahora bien, si estamos ante un libro de cuentos, y no ante una novela o un relato de no ficción, no podemos olvidar que la mayoría de las historias guardan demasiados elementos comunes como para pasarlos por alto. La combinación de los primeros textos del libro es tan fuerte que, en sí misma, da lugar a pensar provisoriamente en un ciclo de cuentos como molde genérico de Un día cualquiera.

En efecto, cuando los relatos se interrelacionan de tal manera que el lector puede experimentarlos como partes de un todo (Ingram, 1971: 19), se suele hablar de ciclo de cuentos. Las diferencias entre los distintos tipos de ciclos son bien importantes, desde $E l$ conde Lucanor o el Decameron hasta Doce cuentos peregrinos o Historia universal de la infamia. Normalmente en todos estos ejemplos se produce una correlación entre las distintas historias, ya sea desde un relato marco que las incluye a todas, ya sea por una idea común que las unifica, como ocurre en los cuentos sobre delincuentes de Historia universal de la infamia, o los viajes de latinoamericanos a Europa en el mentado volumen de García Márquez. Para Miguel Gomes (2000: 564-567) muchos ciclos de cuentos contemporáneos pueden comprenderse desde relaciones de coordinación por parataxis. Esto se produce a través de "las remisiones directas que se producen entre dos o más textos de un mismo autor" (Gomes, 2000: 564), de modo que, a diferencia de las colecciones clásicas del tipo Decamerón, en las que la organización depende de la subordinación de una parte del volumen a otra, todos los cuentos se sujetan por igual a una misma idea. Existen diversas posibilidades de coordinación, ya sea a través de una misma estructura que se repite invariablemente en todos, ya sea por la repetición de personajes, ya sea por una cierta contigüidad temporal, etc.

Un día cualquiera podría atenerse a alguna de las posibilidades señaladas por Gomes. Una de ellas, la más obvia, sería la correlación a través de la narradora-protagonista. El ciclo de cuentos se justificaría por el paso del mismo personaje a través de una serie de relatos.

Los primeros relatos ("Antonio Torno", "Los hermanos Schiavi”, "La tía Celina", "Mi barrio y los vecinos", "El olor de Buenos Aires") se focalizan en la infancia de la narradoraprotagonista y se detienen en múltiples detalles que la sensibilidad infantil dibuja de modo singular: el vecindario, las primeras amistades, el extraño mundo de los adultos. Como hemos visto, cada cuento asumiría la función de capítulo dentro de los cánones del relato de infancia. A pesar de gozar de autonomía propia y tener la capacidad de leerse cada uno por separado, la mirada de la protagonista unifica cada episodio. La perspectiva dual, entre irónica y bañada en ternura recorre estos capítulos.

A partir de "El olor de Buenos Aires", la narradora desgrana sus experiencias fuera del núcleo familiar originario, Moreno, y se va aproximando a las primeras experiencias del mundo adulto, fuera de la protección del hogar. Esas vivencias implican siempre una pérdida 
de la inocencia. El relato arriba mencionado comienza refiriéndose a las lecturas de Rafael Pérez Pérez y las relaciones frustradas entre personas adultas, en concreto, las separaciones. La niña va a saber de las historias de desamor a través del ideario maniqueo y ultraconservador de ciertas novelitas españolas de la época. Este conocimiento libresco se va a ver confrontado con el viaje a la casa de una familiar en Buenos Aires, en donde la narradora capta una situación de separación con las complejidades y matices negados por sus lecturas rosáceas. El relato funciona como un itinerario de aprendizaje en el cual no solo se intuyen conductas de los mayores, sino que se le enseña a no decir lo que no conviene saber. Por eso, cuando la protagonista regresa a Moreno, a las preguntas de la madre sobre lo que ha visto en Buenos Aires, solo responde a medias. El cuento finaliza con un ocultamiento: "Me guardé algunas cosas" (51). Esta reserva frente a la autoridad es un indicio de la actitud que se va a manifestar en los cuatro capítulos siguientes.

De hecho, estas historias se enhebran en torno al mismo personaje en evolución a lo largo del tiempo. El paso de los años se propone explícitamente como un continuum, si nos fijamos en las frases iniciales de cada uno de ellos: "Me recibí de maestra a los dieciséis años" (59, "Maestrita"); "Yo empecé ese año Filosofía y Letras" (71, "Desfulanizar"); "Cuando yo tenía veinte años hice mi primer viaje al exterior..." (75, "Un viaje a La Paz"); "Alrededor de los veintiséis años..." (83, “Turismo urbano").

Cada incipit, pues, se relaciona con los otros por la idea común del transcurso temporal. Atados por la progresión cronológica de la protagonista, los comienzos señalan puntualmente el periodo de vida donde sucederá la acción, de forma que en ella se encierran los jalones iniciáticos correspondientes. Se trata, sobre todo, de posibilidades de enriquecimiento y socialización, desde la primera y fracasada experiencia como profesora de escuela, hasta las primeras relaciones con seres marginales de la capital.

\section{...Y el desvío}

Sin embargo, esta organización se interrumpe a la mitad del volumen cuando la narradora homodiegética desaparece y se da paso a un narrador heterodiegético en los relatos "Historia de una venta" e "¿Y cómo pudo ser?". Aquí, los personajes son otros, nunca han aparecido antes; los espacios son totalmente distintos y la relación con los cuentos anteriores es casi nula.

El orden de la colección, pues, es susceptible de detectarse y, al mismo tiempo, deconstruirse realzando un efecto atomizado que hasta entonces no se había producido. Ciertos rasgos se correlacionan en la lectura y, de pronto, un elemento trastoca la serie y la organización propuesta se invierte o se contradice.

No está sola Hebe Uhart en este tipo de efectos que desorientan una lectura codificada hasta un momento determinado de la narración. Otros cuentistas contemporáneos, como el venezolano Wilfredo Machado, por ejemplo, en su Poética del humo. Antología impersonal (2003), han realizado algo semejante. Este último libro, compuesto de un centenar de textos breves, se organiza mediante una numeración del 1 al 50, pero después vuelve hacia atrás, rompiendo así la serie ascendente de la primera mitad. Para colmo, en la segunda parte, la numeración no se detiene en el 0 , sino que, asimétricamente concluye en el texto titulado "Grado cero". Se impone, por tanto, una tensión contradictoria dentro de dos concepciones 
estructurales: la primera organización se cumple de forma convencional para después invertirse y concluir con una nueva ruptura que quiebra por completo cualquier simetría. ${ }^{3}$

Uhart tampoco gusta de las simetrías ni de concluir de forma perfecta. Por el contrario, mantiene la tensión o, mejor dicho, el desconcierto en su colección. Ello se debe a que el orden estructural expresa la progresiva desorientación existencial de la protagonista. El volumen todavía mantiene una concepción orgánica hasta las primeras aventuras fuera del hogar. Pero después la coherencia estructural se disuelve al tiempo que las direcciones vitales de la protagonista se continúan desdibujando sin un proyecto definido. Tras "Turismo urbano", la ruptura del orden viene marcada por "Historia de una venta", el relato más amplio de la colección. Aquí es donde desaparece la línea narrativa central, hasta el momento, sin ninguna explicación. La narradora se ausenta por completo y la historia sigue los avatares de unos personajes nuevos sin relación con ningún elemento de la ficción contado hasta el momento. Casi nada hay antes que haga prever las humorísticas desventuras de una familia que intenta en vano ponerse de acuerdo para vender una finca de recreo. Ciertamente, en un cuento anterior se alude a la historia de la mujer loca que baña pollos y ahuyenta a gritos a los vecinos. Ahí se descubre un pequeñísimo nexo de "Historia de una venta" con el resto de los capítulos autobiográficos, porque esa mujer "insana" es la "tía María", según cuentan los adultos en una conversación pillada medias por la niña narradora (48). Sin embargo, este fragmento narrativo es un hilo familiar muy débil como para tenerlo en consideración. "Historia de una venta" ya se mueve en direcciones completamente distintas, con personajes y espacios ajenos a la peripecia biográfica de la niña narradora.

La tercera parte, si se puede decir así, del libro, retoma el camino vital de la protagonista narradora, ahora repentinamente adulta. "La ruta es la estructura, uno se puede desviar, pero después hay que volver", comenta Uhart respecto a la composición de sus relatos (Villanueva, 2015: 203). Mutatis mutandis, esto vale también para la organización del libro. Los ocho cuentos finales, desopilantes recuentos de la vida ordinaria de la propia escritora y adulta, se centran en asuntos tan dispares como su visita al zoo, los intentos de dejar de fumar o ciertas experiencias cómicas en la peluquería. Algunas historias se ocupan de desacralizar convenientemente el oficio literario como "La presentación multimedia" o "La coordinación". Este último cuento no solo es un divertido recuerdo del fracaso de Hebe Uhart como moderadora de mesas redondas con escritores, sino que sugiere su incapacidad de establecer un orden fijo en la realidad: "Yo sé mediar, no coordinar" (141).

\section{Descoordinación y fragmentarismo}

Según el DRAE, coordinar es "unir dos o más cosas de manera que formen una unidad o un conjunto armonioso". Y también "unir sintácticamente dos elementos del mismo nivel jerárquico". No convienen demasiado estas definiciones a las ideas que rigen la estructura de Un día cualquiera. Como ya hemos visto, la colección de Hebe Uhart no parece estar gobernada por una férrea coordinación que tienda a la unidad temática. Al principio, el lector tiene la opción de agrupar cada cuento en relación con los que le han precedido y los que le van a suceder. Sin embargo, a la mitad, desde "Historia de una venta" e "¿Y cómo pudo ser?",

\footnotetext{
${ }^{3}$ Para un análisis más detallado, ver Matic, 2017: 237-240.
} 
a este mismo lector se le obliga a eliminar de su conciencia todos los elementos anteriores, de forma que se centre únicamente en las relaciones internas de la pieza individual. La colección, entonces, se desvía de su sentido original, niega la unidad y tiende hacia la fragmentación.

Los cuentos de Un día cualquiera mantienen relaciones heterogéneas entre sí. El libro no es una autobiografía de infancia, pero se le parece. No es un ciclo de cuentos en torno a un mismo tema, aunque la mayoría de ellos se relacionan entre sí. Señala Gomes respecto del ciclo de cuentos: "Un cuento puede leerse como cuento, integrarse en nuestra experiencia como muestra de un género que existe más allá de textos específicos, pero ese mismo cuento puede leerse como un elemento modificado por otros que lo rodean en el lugar tangible del volumen y, a su vez, como modificador de ellos" (2000: 561). Aquí, sin embargo, las modificaciones son demasiado fuertes desde la segunda mitad, para encontrar un nexo común que atraiga a todo el volumen. Cada cuento se dispara hacia distintas anécdotas y escenas, sin que se disponga una jerarquía clara entre una y otra. ${ }^{4} \mathrm{Ni}$ siquiera los relatos que retornan a la figura de la autora, ahora mujer madura, mantienen relaciones de coordinación tan claras como en la primera mitad, ya que no existe un continuum cronológico entre ellos.

"Un día cualquiera", el cuento que no por azar bautiza el libro, resulta ser un comentario metaficcional de todo el conjunto. El vaivén entre orden y fragmentación se advierte desde las primeras líneas. "Me despierto a las cinco o a las seis y pongo la radio para saber la sensación térmica" (161); esta frase inicial puede conectar con los cuentos de la primera mitad que, como ya vimos, comparten una referencia que ordena cronológicamente el relato. En apariencia, para la narradora, es importante situarse en términos numéricos. Es un ideal la exactitud desde el mismo inicio: medir el espacio y el tiempo, es decir, la sensación térmica y la hora ("Porque va más allá de mí: necesito saber la temperatura y la hora" [161]). Sin embargo, enseguida la ironía hace su aparición para enfriar la utilidad de estas reflexiones. Se necesita saber la temperatura porque la autora no quiere ser engañada por la CNN que siempre se equivoca siete grados por encima de Estambul cuando se refiere al clima de Buenos Aires. "Cuánta impostura", refunfuña. En cuanto al interés por la hora, se debe a una obligación autoimpuesta, la de dormir mucho. Una absurda digresión sobre los trucos personales para vencer el insomnio hace olvidar enseguida la importancia de pensar más sobre el tiempo y sus profundidades.

En realidad, desde el inicio, todo el cuento va a ir enhebrando anécdotas mínimas y lugares comunes visitados con una precisa ironía. A un ritmo rápido, la narradora hace un recuento de sus actividades cotidianas desde la primera hora del día: escuchar la radio, dar un paseo errabundo por algún barrio, leer en un café, volver a casa, dormir la siesta, recibir visitas absurdas, tender la ropa... las anécdotas se amontonan sin ton ni son. La memoria de los múltiples acontecimientos sugiere que toda aprehensión de la realidad está teñida de inestabilidad. El fragmento triunfa sobre la concepción unitaria del mundo. ${ }^{5}$ Nada parece más importante que cualquier otra cosa. El encadenamiento de un suceso con otro a veces es directamente absurdo a partir de las reflexiones de la narradora: "Pero lo que sí me gusta

\footnotetext{
4 “La digresión es la alegría del cuento", declara Uhart (en Villanueva, 2015: 200).

5 Como dice Cannavacciuolo, para las crónicas de viaje de Uhart, "la escritura renuncia al afán de crear totalidades [...] y asume los pedazos que la subjetividad de sus personajes produce, captando fragmentos de realidades al paso e interpretándolas en tiempo real" (2012: 113).
} 
mucho es mandar cosas al infierno, o sea, tirarlas a la basura. Lleno con placer el tacho y pareciera que las cosas dijeran «Tirame». Tan a mano y a mi vista se me ponen que me asusta la próxima etapa. ¿Qué pasará? ¿Los objetos saltarán directamente a mi mano? Está nublado. Voy a regar las plantas en memoria mía" (171).

A partir de las cuatro de la tarde faltan ya las ganas de hacer nada. En no pocas ocasiones las acciones vienen precedidas por un deseo de la protagonista, que al final resulta defraudado. Vuelve a casa corriendo por si tiene algún mensaje en el contestador y no lo tiene. Quiere ir al locutorio, pero no se encuentra a su conocida. Pero la frustración no genera desesperación, sino que se resuelve con un humor que atenúa cualquier reflexión sombría. Relato sin jerarquías, en donde ningún elemento arroja una luz sobre el resto, este último cuento ilumina, paradójicamente, la ausencia de orden del libro de Hebe Uhart, su irreductible carácter híbrido, en donde ninguna categoría genérica se impone a la otra de forma completa, porque "ahora es como si todo fuera importante e irrelevante a la vez" (173).

\section{Bibliografía}

ALBERTI, Rafael (1997): La arboleda perdida. Primero y segundo libros (1902-1931). Madrid, Alianza.

BAENA, Rosalía: "La autobiografía de infancia como subgénero narrativo en auge". Rilce XVI/3 (2000): 479-489.

CANNAVACCIUOLO, Margherita: "Más allá del reportaje de viaje: descolocación y alteridad en los cuentos de Hebe Uhart". El hilo de la fábula 12 (2012): 102-115. DOI: https://doi.org/10.14409/hf.v0i12.4699

COE, Richard N. (1984): When the Grass Was Taller. Autobiography and Experience of Childhood. New Haven, Yale University Press.

GANDOLFO, Elvio (2004): "Prólogo". Hebe Uhart: Camilo asciende y otros relatos. Buenos Aires, Interzona: 7-14.

GOMES, Miguel: "El ciclo de cuentos hispanoamericano". Rilce xvi/3 (2000): 557-583.

INGRAM, Forrest L. (1971): Representative Short Story Cycles of the Twentieth Century: Studies in a Literary Genre. La Haya, Mouton.

LEJEUNE, Philipe (1994): El pacto autobiográfico y otros escritos. Madrid, Endymión.

MATIC, Gordana (1917): Aesopus emendatus: La fábula contemporánea iberoamericana. Precursores, exponentes y situación actual. Tesis doctoral inédita. Zagreb, Universidad de Zagreb.

NAVASCUÉS, Javier de: "La novela argentina en busca de una tradición: el caso Mansilla". Rilce XV/1, número monográfico "Del 98 al 98. Literatura e historia literaria en el siglo xx hispánico” (eds. Víctor García Ruiz, Rosa Fernández Urtasun y David K. Herzberger) (1999): 227-238.

PARDO, Carlos (2015): “Arte escondido en lo cotidiano". El País: https://elpais.com/cultura/2015/11/04/babelia/1446640689_553347.html (última consulta: 20/06/2017).

PIGLIA, Ricardo (2001): Crítica y ficción. Barcelona, Anagrama.

UHART, Hebe (1997): Guiando la hiedra. Buenos Aires, Simurg. 
--- (2015): Un día cualquiera. Buenos Aires, Alfaguara.

VILLANUEVA, Liliana (2015): Las clases de Hebe Uhart. Buenos Aires, Blatta y Ríos.

(C) Javier de Navascués

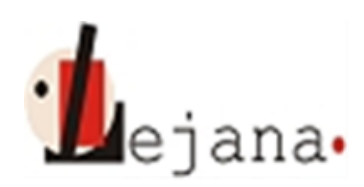

http://ojs.elte.hu/index.php/lejana

Universidad Eötvös Loránd, Departamento de Español, 1088 Budapest, Múzeum krt. 4/C 